OPEN

SUBJECT AREAS:

ENVIRONMENTAL, HEALTH AND SAFETY

ISSUES

GREEN PHOTONICS

Received

7 April 2014

Accepted

27 May 2014

Published

16 June 2014

Correspondence and requests for materials should be addressed to C.F.L. (lincf@ntu.edu. tw)

\section{Environmentally Benign Technology for Efficient Warm-White Light Emission}

\author{
Pin-Chun Shen ${ }^{1,2}$, Ming-Shiun Lin' \& Ching-Fuh Lin ${ }^{1,2,3,4}$
}

'Graduate Institute of Photonics and Optoelectronics, National Taiwan University, No. 1, Section 4, Roosevelt Road, Taipei, 10617 Taiwan (R.O.C.), ${ }^{2}$ Innovative Photonics Advanced Research Center, National Taiwan University, No. 1, Section 4, Roosevelt Road, Taipei, 10617 Taiwan (R.O.C.), ${ }^{3}$ Graduate Institute of Electronics Engineering, National Taiwan University, No. 1, Section 4, Roosevelt Road, Taipei, 10617 Taiwan (R.O.C.), ${ }^{4}$ Department of Electrical Engineering, National Taiwan University, No. 1, Section 4, Roosevelt Road, Taipei, 10617 Taiwan (R.O.C.).

Nowadays efficient down conversion for white light emission is mainly based on rare-earth doped phosphors or cadmium-containing quantum dots. Although they exhibit high luminescence efficiency, the rare-earth mining and cadmium pollution have so far led to extremely high environmental cost, which conflicts the original purpose of pursuing efficient lighting. Here, we explore a new strategy to achieve efficient luminescence conversion based on polymer-decorated nanoparticles. The $\mathrm{ZnO}$ and $\mathrm{Mn}^{2+}$ doped $\mathrm{ZnS}$ nanoparticles are encapsulated by poly(9,9-di-n- hexylfluorenyl-2,7-diyl). The resultant core-shell nanocomposites then encompass three UV-to-visible luminescence conversion routes for photon emissions at blue, green, and orange colors, respectively. As a result, the color temperature is widely tunable $(2100 \mathrm{~K} \sim$ $6000 \mathrm{~K}$ ), so candle light or pure white light can be generated. The quantum yield up to $91 \%$ could also be achieved. Such rare-earth-element free nanocomposites give the bright perspectives for energy-saving, healthy, and environmentally benign lighting.

$\mathrm{T}$ he increasing consciousness of energy crisis like global warming and environmental issues makes people yearn for alternatives energy sources to replace fossil fuels and energy-saving technologies to effectively reduce power consumption ${ }^{1-3}$. At present, $19 \%$ of global electric energy is consumed for illumination. It accounts for $1.9 \mathrm{GT}$ of $\mathrm{CO}_{2}$ emissions ${ }^{4,5}$. Therefore, high-efficiency lighting to significantly reduce global power demands becomes inevitably pressing. In the past decade, solid-state lighting based on III-nitride semiconductors has been considered to be a next-generation light source because they can directly convert electricity to light much more efficiently ${ }^{6,7}$. The current commercial white light-emitting diodes (LEDs) for general illumination so far mainly rely on rare-earth doped phosphors pumped by InGaN/GaN LED chips to down-convert blue or ultraviolet (UV) light to longer wavelength emission ${ }^{8-10}$. This route can possess higher luminous efficacy and lower $\mathrm{CO}_{2}$ emission than conventional lighting system such as incandescent bulbs and fluorescent lamps ${ }^{11}$. However, in view of environmental concerns, one blemish in nowadays white-LED lighting technology is that the luminescence conversion from blue (or UV) light to yellow (or green, red) light excessively rely on the $4 \mathrm{f} \leftrightarrow 5 \mathrm{~d}$ transitions of rareearth elements doped in ceramic-based hosts ${ }^{12}$. The rare-earth mining is a messy and polluting business, which use toxic chemicals and acids to severely destroy the lands and pollute the rivers. The over-exploitation of rare-earth elements has caused heavy damage to the environment over the past few years ${ }^{13-20}$. The high environmental costs such as air emissions with harmful elements and wastewater containing radioactive materials prove objectionable and incompatible to the use of rare-earth doped phosphors. To avoid the misfortunes caused by rare-earth elements, nanocrystal quantum dots (NQDs) have been proposed as an attractive replacement in recent years. Unfortunately, efficient NQDs, such as $\mathrm{CdSe}^{21}, \mathrm{CdS}^{22}$, and $\mathrm{Zn}_{\mathrm{x}} \mathrm{Cd}_{1-\mathrm{x}} \mathrm{Se}^{23}$, contain cadmium, which makes them still unsuitable for environment-friendly purpose ${ }^{24}$. Therefore, providing a new strategy to approach wavelength down-conversion for white-LEDs is an important area that demands further research effort.

Compared to commercial phosphors, which requires sintering at high temperature and doping with high concentration of rare-earth ions to ensure efficient $4 \mathrm{f} \leftrightarrow 5 \mathrm{~d}$ luminescence conversion, polymer/nanoparticle photon emission induced by electron-hole pair recombination at interface states ${ }^{25}$ has a much lower environmental cost. Accordingly, here we explore a new avenue for efficient white light emission based on organic/ inorganic composite interface. By decorating functionalized polymers, poly(9,9-di-n-hexylfluorenyl-2,7-diyl) (PF), on the surfaces of $\mathrm{ZnO}$ and $\mathrm{Mn}^{2+}$ doped $\mathrm{ZnS}$ (ZMS) nanoparticles to form core-shell structures, three physical photon-emission mechanisms for blue, green and orange emission can be designed in the hybrid nanocomposites. In this approach, wide tunablity of color temperature ranging from near $2100 \mathrm{~K}$ to above 
$6000 \mathrm{~K}$, indicating both warm-white light (near candle light) and cool-white light, is attainable. Moreover, due to the rare overlap between the absorption and the emission spectra of the nanocomposites, the self-absorption can be significantly reduced. As a result, the warm white light emission exhibits a high quantum efficiency of $91 \%$. To the best of our knowledge, candle-light photoluminescence from phosphors or semiconductor nanostructures have not been reported before. The proposed concept is environmentally benign and applicable for efficient solid-state lighting.

\section{Results and Discussion}

The optical routes designed in the organic/inorganic composite for luminescence conversion from UV light to white light are depicted in Figure 1a. In an attempt to ensure the luminescence conversion with broad excitation energy from UV to near-UV light being achievable, the hybrid nanocomposites are comprised of three wide band gap materials, $\mathrm{PF}, \mathrm{ZnO}$ and $\mathrm{ZMS}$, which have optical band gaps of $3.2 \mathrm{eV}$, $3.37 \mathrm{eV}$, and $3.54 \mathrm{eV}$ (Supplementary Figure S2), respectively. Therefore, the absorption and electron transference routes will be alternatively dominated by the three matrices from appropriately adjusting the excitation wavelength. When the excitation energy matches the band gap of ZMS and $\mathrm{ZnO}$ nanoparticles, electrons can be promoted from valance band to conduction band of these nanoparticles. Then the electrons at the conduction band of ZMS can transfer back to valence band through ${ }^{4} \mathrm{~T}_{1} \rightarrow{ }^{6} \mathrm{~A}_{1}$ transition of $\mathrm{Mn}^{2+}$ ions, resulting in orange emission ${ }^{26}$. Also, $\mathrm{PF}$ polymer decorated on the surface of these nanoparticles can provide appropriate energy states near the conduction band edge of ZMS and $\mathrm{ZnO}$ nanoparticles so that the electrons can transfer from nanoparticles to PF and further assign to photon emission at blue light through the $\pi^{*} \rightarrow \pi$ transition in PF. Additionally, the $\mathrm{OH}$ groups formed at the $\mathrm{ZnO} /$ $\mathrm{PF}$ heterostructure can attribute to interface states which dominant photon emission corresponding to green light ${ }^{25}$. As a result, UV-towhite luminescence conversion is directly attainable from the surface-functionalized $\mathrm{ZnO}$ and $\mathrm{ZMS}$ nanocomposites, $\mathrm{ZMS}(\mathrm{PF}) \mathrm{ZnO}$. Interestingly, the above-mentioned optical routes can also be activated by the PF polymer even when the excitation energy is lower than the optical gap of the semiconductor nanoparticles. In this case, the PF molecules can function as antennas, absorbing incident photons and transferring their excitation energy to the encapsulated nanoparticles, meaning that the activator for the luminescence conversion is switchable. Figure $1 \mathrm{~b}$ shows the principal concept of the rare-earth-free radiative transitions in the PF-decorated nanoparticles. The schematic structure of a warm-white-light-emitting film constructed by coating $\mathrm{ZMS}(\mathrm{PF}) \mathrm{ZnO}$ nanocomposite on a substrate is shown in Figure 1c.

The morphological characterizations of the as prepared PF-decorated nanoparticles are examined by the measurements of TEM and SEM. Figure 2a shows the TEM image of (6\%)ZMS(PF)ZnO nanocomposites. Here the percentage symbol in (6\%)ZMS(PF)ZnO formula represents the ratio of the weight $(0.3 \mathrm{~g})$ of $\mathrm{ZMS}$ nanoparticles to the volume $(5 \mathrm{ml})$ of solvent. It indicates that the nanoparticles are encapsulated in a low crystalline matrix, revealing that PF covers the surface of the nanoparticles. Additionally, these PF-capped nanoparticles aggregate because the PF molecules on the surface coalesce following the elimination of the solvent during the drying procedure. The aggregation phenomenon can also be observed from the SEM image of PF-ZnO nanocomposites, as shown in Figure 2b. It can be clearly observed that the PF-ZnO nanoparticle composites aggregate with an increasing size compared to the PF-uncovered $\mathrm{ZnO}$ nanoparticles (Supplementary Figure S3). This difference on the morphological characterization strongly supports that PF molecules are coordinated on the surface of nanoparticles, attributing to the aggregations and the increasing size. It implies that the nanoparticles are encapsulated in the PF layer, resulting in an appearance which is similar to core-shell structure.
To demonstrate the excitation-energy-dependent photoluminescence (PL) properties of the hybrid nanocomposites, the emission spectra of (6\%)ZMS(PF)ZnO were measured at different excitation wavelengths ( $365 \mathrm{~nm}, 375 \mathrm{~nm}$ and $385 \mathrm{~nm}$ ). Seen from the PL spectra in Figure 3a, all of the emission profiles are composed of a blue emission peak and a broad green-orange emission band. It indicates that luminescence conversion from UV to white light is certainly achieved in the nanocomposites. The white light generated from (6\%)ZMS(PF) $\mathrm{ZnO}$ is bright and can be directly observed even with naked eyes (Figure $3 \mathrm{~b}$ ). The photoluminescence quantum efficiency (PLQE) is calculated to be $83 \%$ and $91 \%$ upon $365 \mathrm{~nm}$ and $375 \mathrm{~nm}$ excitation, respectively. The highest PLQE is close to that of the commercial phosphor YAG that has PLQE of $95 \%$ under a $450 \mathrm{~nm}$ LED excitation from the same computational method. Details of the computational method for the PLQE are provided in the Supplementary Information.

On the other hand, an enhancement of blue light emission is observed as augmenting the excitation wavelength, leading to the change of emission color. The emission pumped at $365 \mathrm{~nm}$ exhibits warm white light corresponding to a color temperature of $3113 \mathrm{~K}$ with CIE coordinates of $(0.430,0.404)$, which is relatively low compared to most warm-white-light-emitting phosphors reported in other studies $^{27-30}$. Contrarily, the white light emission becomes cooler under $375 \mathrm{~nm}$ and $385 \mathrm{~nm}$ excitation due to the more intense blue light, resulting in a color temperature at $4114 \mathrm{~K}$ and $5213 \mathrm{~K}$, respectively (Supplementary Table S1, Figure S3). The results of the tunable emission properties strongly verify the activator of the white light emission is switchable. Because PF possesses a narrower band gap than $\mathrm{ZnO}$ and $\mathrm{ZnS}$, it can absorb the low-energy photons much more effectively when pumping at a longer wavelength $(385 \mathrm{~nm})$. As a result, the blue luminescence associated with $\pi^{*} \rightarrow \pi$ transition of PF dominates the white light emission. On the other hand, in the $365 \mathrm{~nm}$-excitation case, a greatly enhancement of yellow emission can be observed, originating from the combination of $\mathrm{Mn}^{2+}{ }^{4} \mathrm{~T}_{1} \rightarrow{ }^{6} \mathrm{~A}_{1}$ transition of ZMS nanoparticles and the interface-states transition formed at the polymer/nanoparticle heterojunction. It indicates that the higher-energy photons are mostly absorbed by $\mathrm{ZnO}$ and ZMS nanoparticles. As a result, the number of excited electrons in PF is significantly suppressed, which results in the quenched $\pi^{*} \rightarrow \pi$ blue emission. Consequently, intense warm white light emission is attainable, as shown in Figure $3 \mathrm{~b}$.

Another strong evidence for the switchable absorption antennas is that as augmenting the excitation wavelength, a blue-shift of the PF $\pi^{*} \rightarrow \pi$ emission can be clearly observed. The blue emission has the peak at $420 \mathrm{~nm}$ upon $375 \mathrm{~nm}$ and $385 \mathrm{~nm}$ excitation, which is consistent with the emission peak of pure PF polymer ${ }^{31}$. However, when the excitation wavelength is adjusted to $365 \mathrm{~nm}$, the blue emission peak shifts to $447 \mathrm{~nm}$. This red-shifted peak certainly points out that the excited electrons of PF relax from lower excited states, leading to an incomplete $\pi^{*} \rightarrow \pi$ transition. As a result, a red-shifted blue emission at $447 \mathrm{~nm}$ can be observed. This fact evidently confirms the occurrence of energy transference between PF and nanoparticles. It indicates that the $365 \mathrm{~nm}$ photon energy is mainly absorbed by the nanoparticles. After the nanoparticles absorb the UV light, the electron is promoted from the valence band to the conduction band. The excited electron then transfers to PF and occupies the lower excited states, which are close to the conduction band edge of the nanoparticles. Therefore, the relaxation from the lower excited states to the ground state leads to the red-shifted blue emission peak at $447 \mathrm{~nm}$.

Because the yellow emission $(500-700 \mathrm{~nm})$ is governed by the recombination of charge carriers at the interface states and ${ }^{4} \mathrm{~T}_{1}{ }^{-}{ }^{6} \mathrm{~A}_{1}$ states of $\mathrm{Mn}^{2+}$, their energy level would not be remarkably changed by the direction of the electron transference. Hence one can notice that the yellow emission band shows no obvious shift with augmenting the excitation wavelength.

The above-mentioned phenomena demonstrate that the energytransference mechanisms can be driven by the nanoparticles and PF 
a
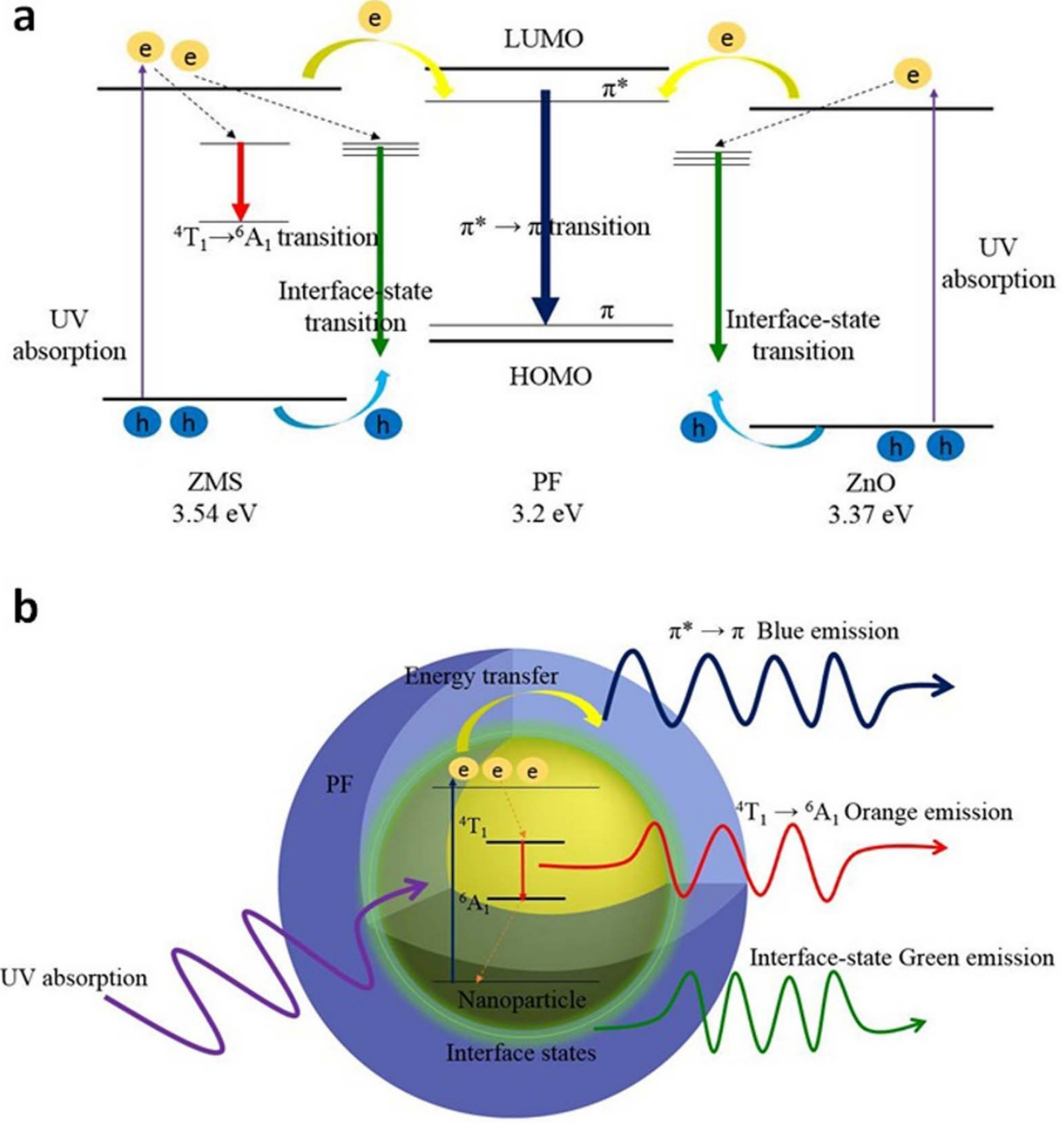

C

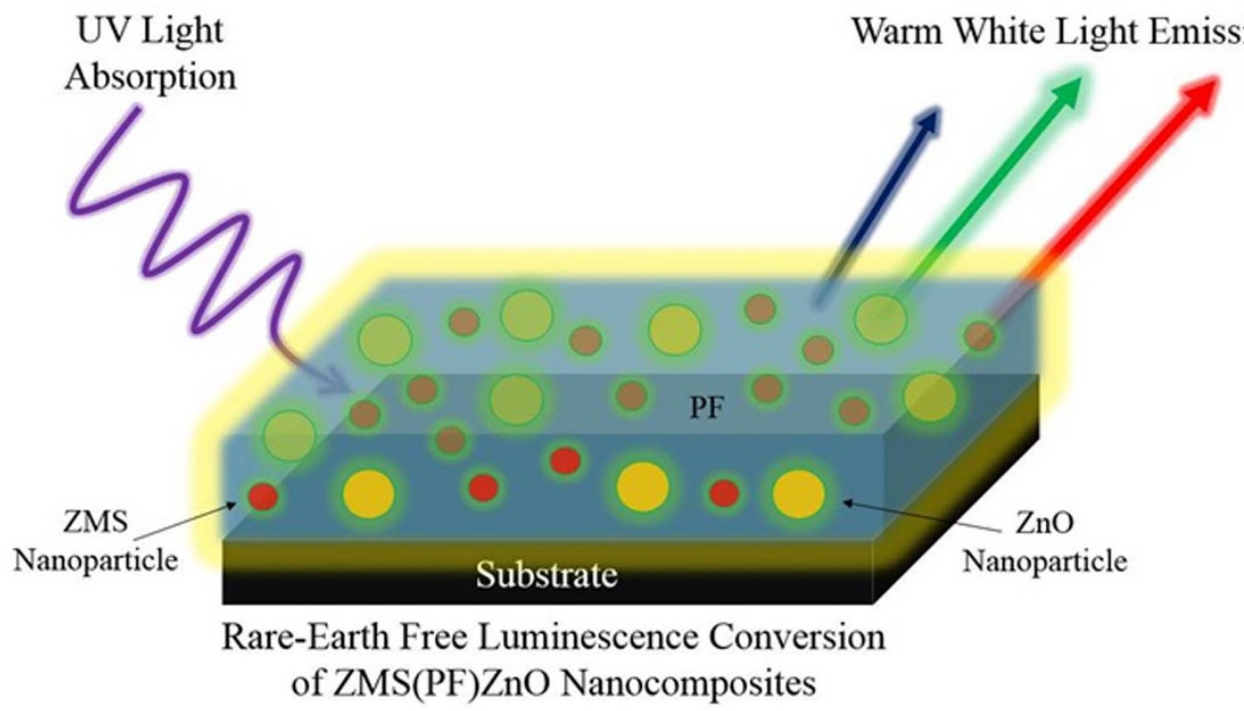

Figure $1 \mid$ Photon-emission mechanisms and structure of ZMS(PF)ZnO nanocomposites. (a), Schematic diagram for radiative recombinations of $\mathrm{ZMS}(\mathrm{PF}) \mathrm{ZnO}$ nanocomposites under UV excitation. The pathways of electrons and holes are indicated by arrows. (b), Principal concept of the rareearth-free radiative routes in the PF-decorated nanoparticles. (c), Schematic structure of core-shell ZMS(PF)ZnO nanocomposites coated on a substrate. 


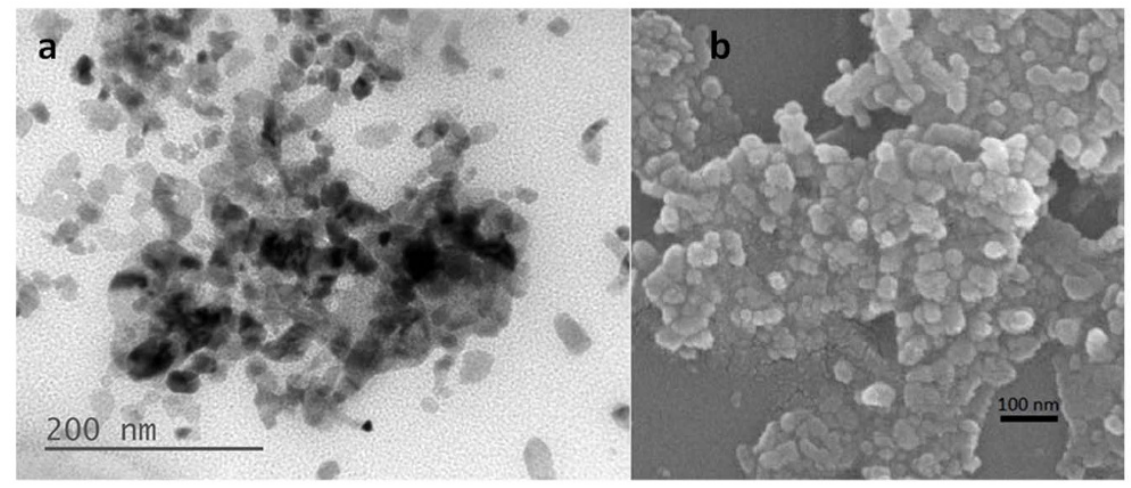

Figure $2 \mid$ Morphological characterizations of the as prepared PF-decorated nanoparticles. (a), TEM image of 6(\%)ZMS(PF)ZnO nanocomposites. (b), SEM image of PF-capped $\mathrm{ZnO}$ nanoparticles.

molecules alternately, depending on the excitation energy. When the excitation energy is lower than the band gaps of ZMS and $\mathrm{ZnO}$ nanoparticles, the absorption route of the nanocomposites is from PF and thus a complete $\pi^{*} \rightarrow \pi$ emission at $420 \mathrm{~nm}$ can be attained. Otherwise, the absorption and energy transference will be dominated by nanoparticles as at high-energy excitation because of their wider band gaps. Since the photon-absorption antennas in $\mathrm{ZMS}(\mathrm{PF}) \mathrm{ZnO}$ nanocomposites are wavelength-dependent, the emission color of white light is systematically tunable.

The above results show that warm white light emission is attainable from $\mathrm{ZMS}(\mathrm{PF}) \mathrm{ZnO}$ nanocomposites upon a shorter excitation wavelength. It is known that the color temperature has a significant influence on human physiology and psychology ${ }^{32,33}$. Recent studies have indicated that white light with a high color temperature can
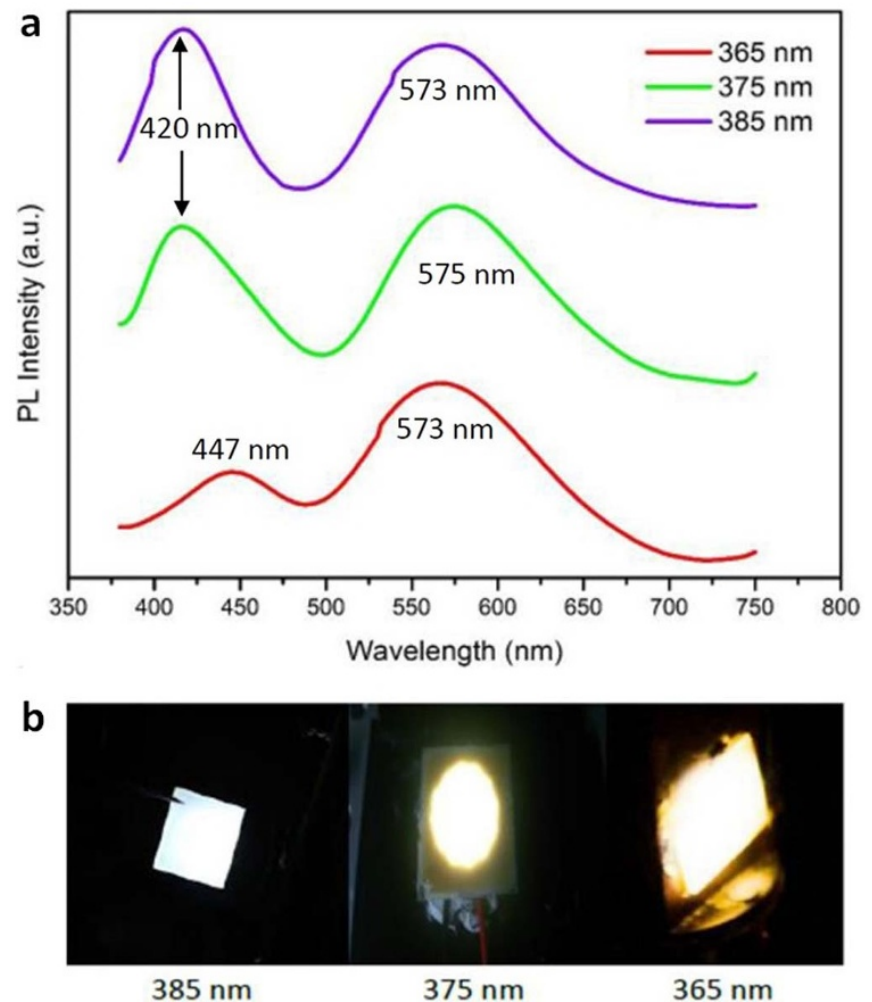

Figure 3 Switchable optical absorption center of $\mathrm{ZMS}(\mathrm{PF}) \mathrm{ZnO}$ nanocomposites. (a), Photoluminescence emission spectra of (6\%)ZMS(PF)ZnO at different excitation wavelength. (b), Photo images of (6\%)ZMS(PF)ZnO at $365 \mathrm{~nm}, 375 \mathrm{~nm}$ and $385 \mathrm{~nm}$ excitation, respectively. drastically suppress the generation of melatonin. The lack of melatonin could result in insomnia and an increased cancer risk ${ }^{34-38}$. Consequently, to bulwark human health, it is important to explore low color temperature white-light-emitting materials. In spite of the strong demand for low-color- temperature lighting, no report, to our knowledge, has found fluorescent materials to exhibit color temperature of $<3000 \mathrm{~K}$ for nitride-based LEDs before. According to the distinctive optical properties of the hybrid nanocomposites presented in this study, the thorny problem can be preliminarily approached fortunately.

In order to achieve an even lower color temperature, it is necessary to maximize the green-orange-dominant emission and to minimize the blue counterpart. Therefore, the dosages of ZMS nanoparticles are increased to reduce the blue emission and to improve the greenorange light region. The UV-vis absorption and PL emission spectra of (6\%)ZMS(PF)ZnO and (7.2\%)ZMS(PF)ZnO hybrid compounds are depicted in Figure 4a. Seen from the absorption spectra, a strong absorption in the UV region caused by the fundamental band-toband absorption of $\mathrm{ZnS}$ host and $\mathrm{ZnO}$ nanoparticles is observed. The absorption is strong and broad with respect to the UV region $(350 \mathrm{~nm} \sim 400 \mathrm{~nm})$ and relatively low in the visible region. It implies that the self-absorption can be effectively reduced, which ascribes to the high quantum efficiency.

Figure $4 \mathrm{a}$ also shows that the PL spectra $\left(\lambda_{\text {exc. }}=325 \mathrm{~nm}\right)$ of (6\%)ZMS(PF)ZnO and (7.2\%)ZMS(PF)ZnO exhibit a similar emission profile, with a blue emission peak located at $440 \mathrm{~nm}$ and a broad emission band covering the green-orange spectral region from $500 \mathrm{~nm}$ to $650 \mathrm{~nm}$. Notice that in the cases of these two nanocomposites, the green-orange emission presents a much higher intensity than the blue one, indicating that the yellow light is predominant in the white light emission. Consequently, from the CIE chromaticity diagram shown in Figure $4 \mathrm{~b}$, the white light emissions from (6\%)ZMS(PF) $\mathrm{ZnO}$ and (7.2\%)ZMS(PF) $\mathrm{ZnO}$ are in the yellow region, corresponding to very low color temperatures. The color coordinate and the color temperature of $(6 \%) \mathrm{ZMS}(\mathrm{PF}) \mathrm{ZnO}$ are $(0.459,0.410)$ and $2602 \mathrm{~K}$, respectively. As the dosage of ZMS nanoparticles increases to $7.2 \%$, a red-shifted chromaticity coordinates of $(0.468,0.411)$ is observed. Thus (7.2\%)ZMS(PF)ZnO gives a color temperature as low as $2118 \mathrm{~K}$, which extremely approaches the candle light.

Note that the incomplete $\pi^{*} \rightarrow \pi$ transition corresponding to the red-shifted $440 \mathrm{~nm}$ peak is observed again in the emission spectra of both (6\%)ZMS(PF) ZnO and (7.2\%)ZMS(PF)ZnO. It can be concluded that the energy or, more specifically, the excited electron is transferred from the nanoparticles to the PF as excitation at $325 \mathrm{~nm}$. In addition, in the case of (7.2\%)ZMS(PF) ZnO, the significant enhancement of the green emission peak centered at $550 \mathrm{~nm}$ and the orange emission peaked at $610 \mathrm{~nm}$ is also observed, indicating that the excess ZMS nanoparticles would lead to a large number of interface states within the hybrid nanocomposites. Thus after elec- 

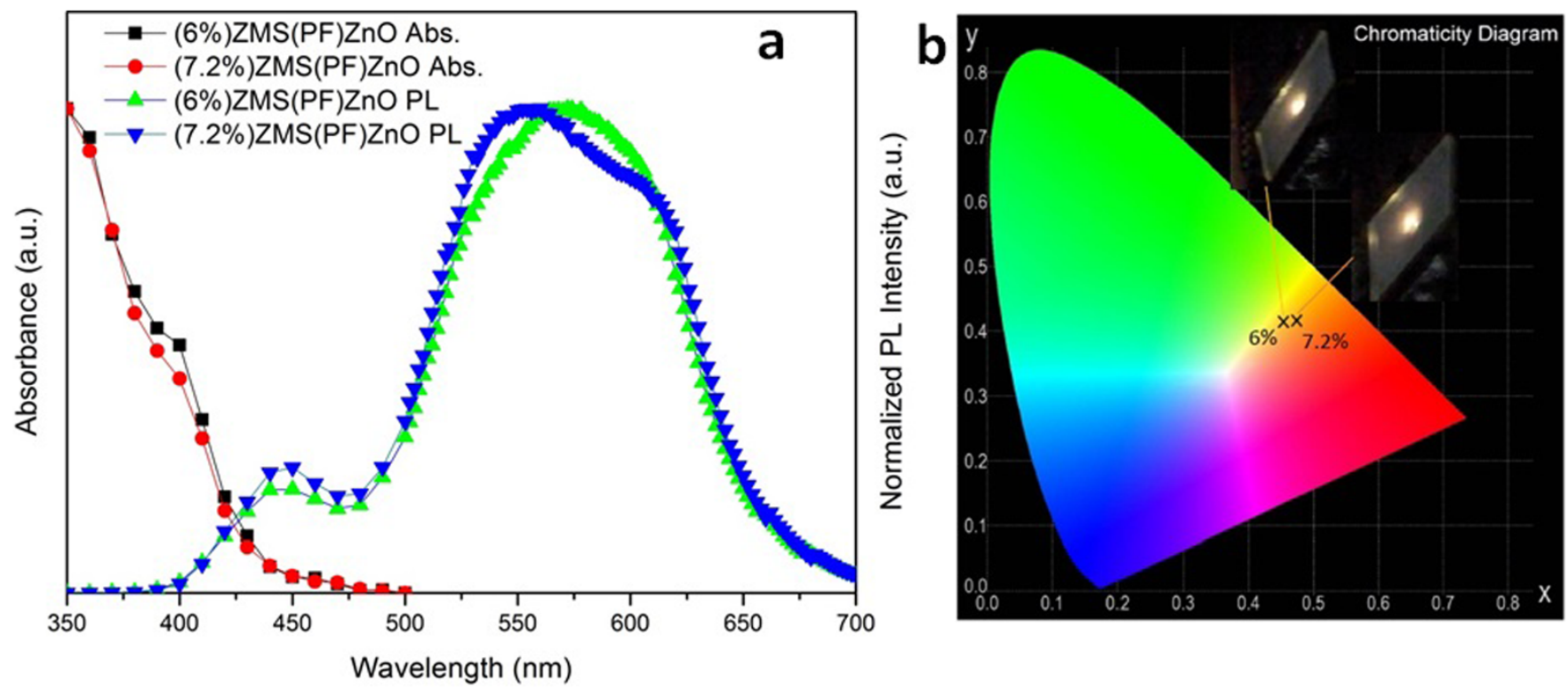

Figure $4 \mid$ Optical properties of the prepared candle-light nanocomposites. (a), UV-vis absorption (Abs.) and photoluminescence spectra (at $325 \mathrm{~nm}$ excitation) of ZMS(PF)ZnO with different ZMS concentrations (6\% and 7.2\%). (b). CIE chromaticity diagram for (6\%)ZMS(PF)ZnO and $(7.2 \%) \mathrm{ZMS}(\mathrm{PF}) \mathrm{ZnO}$ at an excitation wavelength of $325 \mathrm{~nm}$.

trons are promoted from the valence band to the conduction band of the ZMS nanoparticles, part of the excited electrons from the nanoparticles will be trapped at the interface states when transferring across the interface to the PF. Before relaxing back to the ground state via a nonradioactive pathway, the trapped electrons will recombine with the photogenerated holes and then give rise to the green emission observed on the PL spectra. Therefore, the increment of ZMS nanoparticles not only results in the enhanced orange-red region but also greatly improves the interface-state-related green emission, which causes the red shift observed in the chromaticity diagram.

We next demonstrate that the white light emission from the hybrid system is widely tunable from cool light to warm light. Figure 5a shows the PL spectra of the hydrothermally prepared $\mathrm{ZnS}: \mathrm{Mn}$ (ZMS) nanoparticles, $\mathrm{PF}, \mathrm{ZnO}$ nanoparticles, $\mathrm{PF}(\mathrm{ZnO})$ and (2\%)ZMS(PF)ZnO hybrid nanocomposites excited at $325 \mathrm{~nm}$. In the case of (PF) ZnO, there are two emission bands at 400-475 nm and 500-600 nm, corresponding to blue and green components, respectively. Due to the red spectral deficiency, the emission of (PF) $\mathrm{ZnO}$ is cool, bluish white light, exhibiting chromaticity coordinates and a color temperature of $(0.312,0.329)$ (Figure $5 b$ ) and $6540 \mathrm{~K}$, respectively. Seen from Figure $5 \mathrm{a}$, one can notice that the green luminescence of $\mathrm{PF}(\mathrm{ZnO})$ peaked at $530 \mathrm{~nm}$ is not observed from pure $\mathrm{PF}$ and $\mathrm{ZnO}$ nanoparticles. Many studies have reported that the presence of oxygen vacancy and interstitial zinc defects in $\mathrm{ZnO}$ nanostructures can also lead to visible emission ${ }^{39-41}$. However, in this work, we observed that the green luminescence from the prepared $\mathrm{PF}(\mathrm{ZnO})$ nanocomposites is much stronger than the defect-related emission of $\mathrm{ZnO}$ nanoparticles. The resultant white luminescence is bright and observable with naked eyes. From the PL spectra of $\mathrm{PF}(\mathrm{ZnO})$ nanocomposites and $\mathrm{ZnO}$ nanoparticles, the difference in emission intensity can be further quantified. By making comparison of absolute emission intensities between $\mathrm{PF}(\mathrm{ZnO})$ nanocomposites and $\mathrm{ZnO}$ nanoparticles, we observed that the defectrelated visible emission $(500-700 \mathrm{~nm})$ of pure $\mathrm{ZnO}$ nanoparticles is very weak (black line). The dominant emission peak of $\mathrm{ZnO}$ nanoparticles is in UV region, located at $385 \mathrm{~nm}$, which is ascribed to the free exciton at the near band edge ${ }^{42}$. Compared to $\mathrm{ZnO}$ nanoparticles, the green luminescence from $\mathrm{PF}(\mathrm{ZnO})$ nanocomposites exhibits a much stronger PL intensity. Moreover, the visible emission profile
$(500-700 \mathrm{~nm})$ of the pure $\mathrm{ZnO}$ nanoparticles is obviously not in accordance with the green emission profile (peaked at $530 \mathrm{~nm}$ ) from $\mathrm{PF}(\mathrm{ZnO})$ nanocomposites. It certainly implies that the emission routes are attributed to different energy states. According to the results, we infer that the green luminescence of $\mathrm{PF}(\mathrm{ZnO})$ is associated with the interface-trap states of $\mathrm{ZnO} / \mathrm{PF}$ heterojunction rather than the defect levels in $\mathrm{ZnO}$ crystal.

Time resolved PL (TRPL) measurements were also performed to further investigate the mechanisms involved in the emission process of the $\mathrm{PF}(\mathrm{ZnO})$ nanocomposites. The emission wavelengths were monitored at $420 \mathrm{~nm}$ and $530 \mathrm{~nm}$, corresponding to the blue emission and green emission of $\mathrm{PF}(\mathrm{ZnO})$, respectively. The emission decay curves of $\mathrm{PF}(\mathrm{ZnO})$ sample are shown in Figure $5 \mathrm{c}$. The decay curves can be described by a standard two-exponential-component model. Therefore, emission lifetimes then can be calculated from the decay time of the two exponential components and the pre-exponential factors (see Supplementary Information). Accordingly, we have obtained the two emission lifetimes $\tau_{\mathrm{b}}=0.3791 \mathrm{~ns}$ and $\tau_{\mathrm{g}}=$ $5.935 \mathrm{~ns}$ for the blue emission and green emission, respectively. Note that the green emission exhibits a much longer carrier lifetime than that of the blue emission. The slower decay result supports that the green emission is interface-trap-state associated recombination. It illustrates that the photogenerated electrons involve in transferring to the surface and then recombining with holes at $\mathrm{ZnO} / \mathrm{PF}$ interface states, therefore, leading to a longer decay lifetime.

As the $2 \%$ of ZMS nanoparticles are introduced, the chromaticity coordinate of the white light gradually shifts to the yellow region, indicating both the green and orange spectral components have been enhanced. It is in accordance with the results of PL spectra shown in Figure $5 \mathrm{a}$. It is worth noting that $(2 \%) \mathrm{ZMS}(\mathrm{PF}) \mathrm{ZnO}$ exhibits the CIE coordinate of $(0.330,0.345)$. It is very close to the pure white light $(0.33,0.33)$. The results demonstrate that the color temperature of the white light emission is systematically tunable by controlling the ZMS nanoparticle content. Hence the emission color of the nanocomposites is widely tunable from cool light to warm light.

In conclusion, we have demonstrated a judicious design strategy to achieve warm white light emission by polymer-decorated semiconductor nanoparticles. The PF molecules and the nanoparticles can function as antennas, alternately dominating the absorption of 

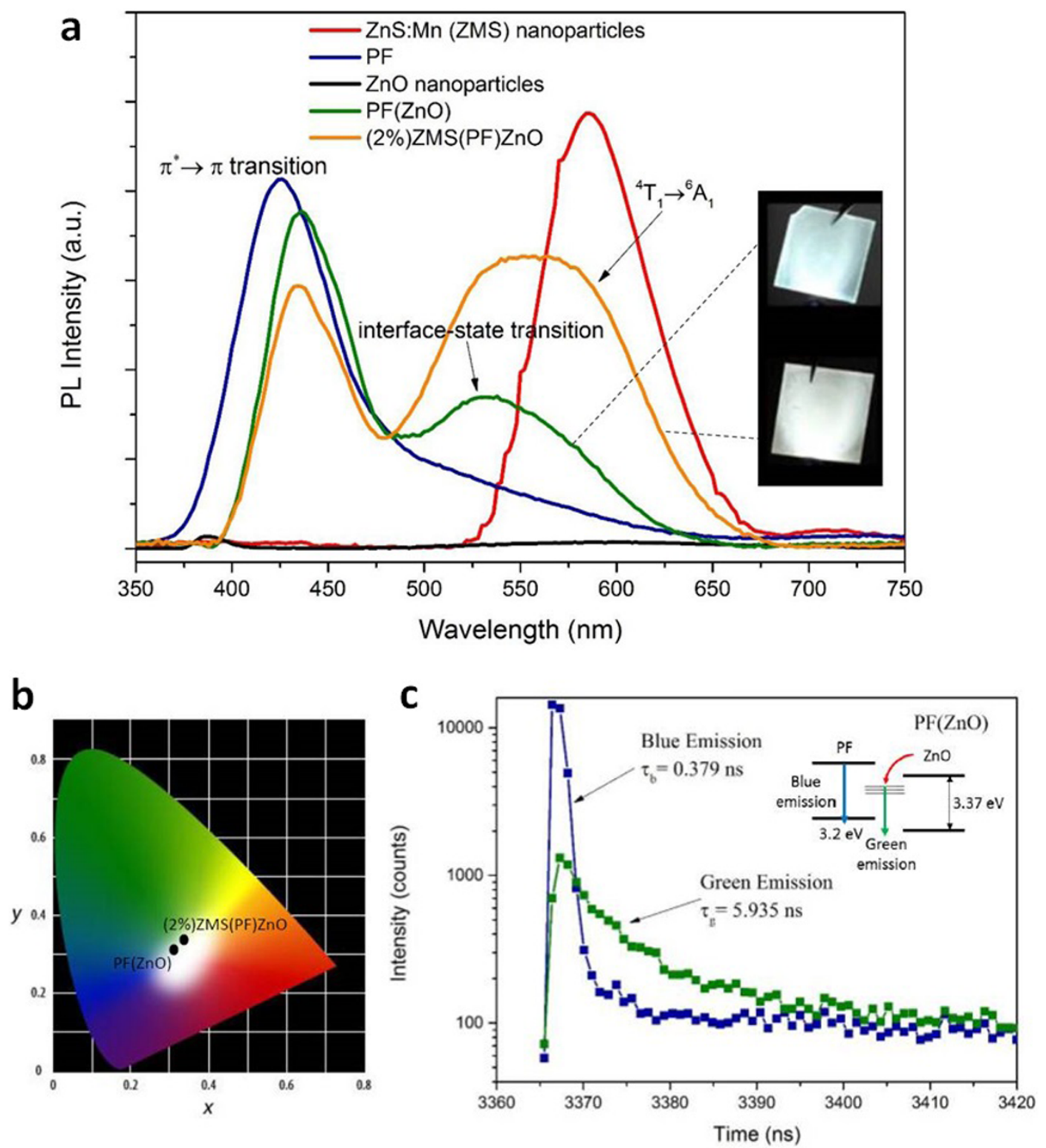

Figure 5 Tunable white light emission from ZMS(PF)ZnO nanocomposites. (a), Photoluminescence emission spectra of ZMS nanoparticles, PF, ZnO nanoparticles, $\mathrm{PF}(\mathrm{ZnO})$ and (2\%)ZMS(PF)ZnO (at $325 \mathrm{~nm}$ excitation). (b), Chromaticity coordinates of (PF)ZnO and (2\%)ZMS(PF)ZnO on CIE 1931 diagram. (c). TRPL traces of the (PF) $\mathrm{ZnO}$ emission, showing the lifetime of the blue luminescence and the green luminescence in the (PF) ZnO nanocomposites are 0.379 ns and $5.935 \mathrm{~ns}$, respectively.

incident photons and the transference of excitation energy as pumping at different wavelengths. In the strategy, complex rare-earth doping process and cadmium-containing quantum dots are avoided. Instead, the UV-to-white luminescence conversion of the hybrid nanocomposites is implemented by three fundamental electron-hole-recombination routes, namely, green emission from the interface states, orange emission from the ${ }^{4} \mathrm{~T}_{1}{ }^{-}{ }^{6} \mathrm{~A}_{1}$ transition of $\mathrm{Mn}^{2+}$, and blue emission from $\pi^{*} \rightarrow \pi$ transition of PF. The nanocomposites can emit bright white light with systematically tunable emission properties. Benefiting from the co-existence of several radiative recombination routes, color temperature is widely tunable from $2100 \mathrm{~K}$ to $6000 \mathrm{~K}$, covering both candle light and pure white light. High quantum yield up to $91 \%$ can also be achieved. The new strategy not only offers a rare-earth-free white-light-emitting technology to achieve eco-friendly propose, but also gives high quantum efficiency. This novel approach opens a new avenue for the exploration of high performance, environmentally friendly and house lighting white phosphors.

\section{Methods}

Materials. $\mathrm{Zn}\left(\mathrm{NO}_{3}\right) \cdot 6 \mathrm{H}_{2} \mathrm{O}$ (J.T.Baker, $\left.99.999 \%\right), \mathrm{Mn}\left(\mathrm{CH}_{3} \mathrm{COO}\right)_{2} \cdot 4 \mathrm{H}_{2} \mathrm{O}$ (SigmaAldrich, 99+\%), poly (9,9-di-n-hexylfluorenyl-2,7-diyl) (Sigma-Aldrich), $\mathrm{Na}_{2} \mathrm{~S} \cdot 9 \mathrm{H}_{2} \mathrm{O}$ (Alfa Aesar, 98\%), Toluene (Sigma-Aldrich, $99.7 \%$, A.C.S. Reagent) and $\mathrm{ZnO}$ nanoparticles (First Chemical Works, 99.7\%) were used as received without further purification. The excitation sources of $365 \mathrm{~nm}, 375 \mathrm{~nm}$ and $385 \mathrm{~nm}$ UV LEDs were purchased from KOODYZ Technology Co., Ltd.

Synthesis of ZnS:Mn Nanoparticles. ZnS:Mn (ZMS) nanoparticles were prepared by a hydrothermal method. At first, $20 \mathrm{mmol}$ of zinc acetate were dissolved in $40 \mathrm{ml}$ of de-ionized water. After dissolving $0.5 \mathrm{mmol}$ of manganese acetate into the above solution, the mixture was stirred for $30 \mathrm{~min}$. The $\mathrm{PH}$ value of the solution was maintained at 11 by adding the $\mathrm{NaOH}$ solution. Then, the solution was added drop wise with $20 \mathrm{ml}$ of aqueous containing $20 \mathrm{mmol}$ of sodium sulfide; it was continuously stirred at $180^{\circ} \mathrm{C}$ for $3 \mathrm{~h}$. The product was filtered out, washed several times with ethanol to remove sodium particles, and dried under air as purified ZMS nanoparticles.

Synthesis of ZMS(PF)ZnO Nanocomposites. First, $0.02 \mathrm{~g}$ of poly(9,9-di-nhexylfluorenyl-2,7-diyl) was dissolved in $5 \mathrm{ml}$ of toluene. ZnO nanoparticles of $0.05 \mathrm{~g}$ were added to the above solution with stirring. The reaction was heated at $80^{\circ} \mathrm{C}$ for 
30 min to obtain PF- $\mathrm{ZnO}$ composite solution. Then, the ( $\mathrm{x} \%) \mathrm{ZMS}(\mathrm{PF}) \mathrm{ZnO}(\mathrm{x}=2,6$, 7.2) nanocomposites containing various amounts of $\mathrm{ZnS}: \mathrm{Mn}$ (ZMS) nanoparticles were synthesized by adding $0.10 \mathrm{~g}, 0.30 \mathrm{~g}$ and $0.36 \mathrm{~g}$ of the as-prepared ZMS nanoparticles to the PF-ZnO solution. Herein the percentage symbol of the $(\mathrm{x} \%) \mathrm{ZMS}(\mathrm{PF}) \mathrm{ZnO}$ formula represents the ratio of the weight $(\mathrm{g})$ of ZMS nanoparticles to the volume (ml) of solvent. After the addition of ZMS nanoparticles, the mixture solution was heated at $80^{\circ} \mathrm{C}$ for $2 \mathrm{~h}$.

Fabrication of White-light-emitting Fluorescent Films. As the substrates, glass slabs were cleaned by ultrasonic agitation in acetone, isopropyl alcohol, de-ionized water sequentially, and then dried with nitrogen gun. The fluorescent film was formed by spin-coating ( $2000 \mathrm{rpm}$ for $80 \mathrm{~s}$ ) the nanocomposite solution onto the substrate surface. Then, the film was dried at $150^{\circ} \mathrm{C}$ under air for $2 \mathrm{~h}$ to remove the solvent. After cooling to room temperature, fluorescent films with different ZMS concentrations were obtained.

Measurements. The crystal characterization of the ZMS nanoparticles was examined using an X-ray diffraction (XRD) meter (X'PERT) with a $\mathrm{Cu} \mathrm{K} \alpha$ radiation source $(\lambda=$ $0.15406 \mathrm{~nm}$ ) operated at $45 \mathrm{kV}$ and $40 \mathrm{~mA}$ with a step size of $0.02^{\circ}$. The morphologies were imaged and analyzed using a scanning electron microscope (SEM, JEOL JSM-6500F) and a transmission electron microscope (TEM, JEOL JEM-1200EX II). The emission and excitation properties of the ZMS nanoparticles were measured at room temperature vsia using a modular fluorescence spectrophotometer (HitachiF-4500, Tokyo, Japan) with a Xenon lamp as the light source. The photoluminescence (PL) spectra of the $\mathrm{ZMS}(\mathrm{PF}) \mathrm{ZnO}$ nanocomposites excited at $325 \mathrm{~nm}, 365 \mathrm{~nm}, 375 \mathrm{~nm}$ and $385 \mathrm{~nm}$ were measured at room temperature by using a $325 \mathrm{~nm}$ continuous-wave He-Cd laser, $365 \mathrm{~nm}, 375 \mathrm{~nm}$ and $385 \mathrm{~nm}$ UV LED as the light source, respectively. The experimental setup of system used for measuring the PL spectra of samples is schematically depicted in Supplementary Information. The color temperature and CIE chromaticity coordinates of the samples were measured at room temperature using a Hong-Ming TECH Optic plug-and-play spectrometer. Time-resolved photoluminescence (TRPL) spectroscopy were recorded using an Edinburgh FL 900 photo-counting system (Edinburgh Instruments, Livingston, UK), with a $377 \mathrm{~nm}$ pulsed laser (Spectra Phys, Irvine, CA, USA) employed as an excitation source (pulse rate: $6 \mathrm{~ns}$ ) and a $440 \mathrm{~nm}$ narrow bandpass filter utilized to minimize scattering light. The emission wavelengths were monitored at $420 \mathrm{~nm}$ and $530 \mathrm{~nm}$. Details of the measuring method of the photoluminescence quantum efficiency (PLQE) are provided in the supporting information.

1. Dresselhause, M. S. \& Thomas, I. L. Alternative energy technologies. Nature 414, 332-337 (2001).

2. Change, I. P. O. C. Climate change 2007: the physical science basis. Agenda 6, (2007).

3. Smith, R., Liu, B., Bai, J. \& Wang, T. Hybrid III-nitride/organic semiconductor nanostructure with high efficiency nonradiative energy transfer for white light emitters. Nano Lett. 13, 3042-3047 (2013).

4. Taguchi, T. Present status of energy saving technologies and future prospect in white LED lighting. IEEJ T. Electr. Electr. 3, 21-26 (2008).

5. Hahn, B. High power LEDs for solid state lighting. Solid-State Device Research Conference: 2010 Proceedings of the European, Sevilla, Spain. IEEE 57-63 (DOI 10.1109/ESSDERC.2010.5617734) (2010).

6. Pimputkar, S., Speck, J. S., DenBaars, S. P. \& Nakamura, S. Prospects for LED lighting. Nat. Photonics 3, 180-182 (2009).

7. Reineke, S. et al. White organic light-emitting diodes with fluorescent tube efficiency. Nature 459, 234-238 (2009)

8. Narukawa, Y. White-light LEDS. Opt. Photonics News 15, $24-29$ (2004).

9. Uchida, Y. \& Taguchi, T. Lighting theory and luminous characteristics of white light-emitting diodes. Opt. Eng. 44, 124003-124009 (2005).

10. Ye, S., Xiao, F., Pan, Y., Ma, Y. \& Zhang, Q. Phosphors in phosphor-converted white light-emitting diodes: Recent advances in materials, techniques and properties. Mat. Sci. Eng. R. 71, 1-34 (2010).

11. Tonzani, S. Lighting technology: Time to change the bulb. Nature 459, 312 (2009).

12. Lin, C. C. \& Liu, R.-S. Advances in phosphors for light-emitting diodes. J. Phys. Chem. Lett. 2, 1268-1277 (2011)

13. Hurst, C. The rare earth dilemma: China's rare earth environmental and safety nightmare. The Cutting Edge (November 15, 2010) Date of access: 11/11/2012. Retrieved from http://www.thecuttingedgenews.com/index.php?article $=21777$.

14. Mooney, E. Eastern abandoned mines project. Trout Unlimited Date of access: $27 /$ 12/2013. Retrieved from http://www.tu.org/tu-projects/eastern-abandonedmines-project.

15. Mission 2016: The Future of Strategic Natural Resources. Environmental Damage. Massachusetts Institute of Technology Date of access: 15/1/2014. Retrieved from http://web.mit.edu/12.000/www/m2016/finalwebsite/.

16. Bradsher, K. Mitsubishi quietly cleans up its former refinery. The New York Times (March 8, 2011) Date of access: $26 / 3 / 2013$. Retrieved from http://www.nytimes. com/2011/03/09/business/energy-environment/09rareside.html?_r $=0$.

17. Margonelli, L. Clean energy's dirty little secret. The Atlantic (May 1, 2009) Date of access: 13/10/2013. Retrieved from http://www.theatlantic.com/magazine/ archive/2009/05/clean-energys-dirty-little-secret/307377/.
18. Miranda, M., Blanco Uribe, Q. A., Hernández, L., Ochoa, G. \& Yerena, E. All that glitters is not gold: balancing conservation and development in Venezuela's frontier forests. World Resources Institute (April, 1998) Date of access: 2/1/2014. Retrieved from http://www.wri.org/publication/all-glitters-not-gold.

19. Paul, J. \& Campbell, G. Investigating rare earth element mine development in EPA region 8 and potential environmental impacts. A National Service Center for Environmental Publications EPA document-908R11003 (August 15, 2011) Date of access: $28 / 12 / 2013$

20. Human health and environmental damages from mining and mineral processing wastes. U.S. Environmental Protection Agency, Office of Solid Waste (December, 1995) Date of access: $3 / 1 / 2014$. Retrieved from http://www.epa.gov/osw/nonhaz/ industrial/special/mining/minedock/damage/damage.pdf.

21. Bowers, M. J., McBride, J. R. \& Rosenthal, S. J. White-light emission from magicsized cadmium selenide nanocrystals. J. Am. Chem. Soc. 127, 15378-15379 (2005).

22. Sapra, S., Mayilo, S., Klar, T. A., Rogach, A. L. \& Feldmann, J. Bright white-light emission from semiconductor nanocrystals: by chance and by design. Adv. Mater. 19, 569-572 (2007).

23. Shen, C.-C. \& Tseng, W.-L. One-step synthesis of white-light-emitting quantum dots at low temperature. Inorg. Chem. 48, 8689-8694 (2009).

24. Erdem, T. \& Demir, H. V. Semiconductor nanocrystals as rare-earth alternatives. Nat. Photonics 5, 126-126 (2011).

25. Lee, C. et al. White-light electroluminescence from $\mathrm{ZnO}$ nanorods/polyfluorene by solution-based growth. Nanotechnology 20, 425202 (2009).

26. Bhargava, R., Gallagher, D., Hong, X. \& Nurmikko, A. Optical properties of manganese-doped nanocrystals of ZnS. Phys. Rev. Lett. 72, 416 (1994).

27. Sava, D. F., Rohwer, L. E., Rodriguez, M. A. \& Nenoff, T. M. Intrinsic broad-band white-light emission by a tuned, corrugated metal-organic framework. J. Am. Chem. Soc. 134, 3983-3986 (2012).

28. Dai, Q., Foley, M. E., Breshike, C. J., Lita, A. \& Strouse, G. F. Ligand-passivated Eu: Y2O3 nanocrystals as a phosphor for white light emitting diodes. J. Am. Chem. Soc. 133, 15475-15486 (2011).

29. Im, W. B. et al. Efficient and color-tunable oxyfluoride solid solution phosphors for solid-state white lighting. Adv. Mater. 23, 2300-2305 (2011).

30. Li, X. et al. New yellow Ba0. 93Eu0. 07Al2O4 phosphor for warm-white light-emitting diodes through single-emitting-center conversion. Light Sci. Appl. 2, e50 (2013).

31. Lu, H.-H. et al. Excimer formation by electric field induction and side chain motion assistance in polyfluorenes. Macromolecules 38, 10829-10835 (2005).

32. Brainard, G. C. et al. The influence of various irradiances of artificial light, twilight, and moonlight on the suppression of pineal melatonin content in the Syrian hamster. J. Pineal Res. 1, 105-119 (1984).

33. Van Bommel, W. J. Non-visual biological effect of lighting and the practical meaning for lighting for work. Appl. Ergonomics 37, 461-466 (2006).

34. Blask, D. E. et al. Melatonin-depleted blood from premenopausal women exposed to light at night stimulates growth of human breast cancer xenografts in nude rats. Cancer Res. 65, 11174-11184 (2005)

35. Pauley, S. M. Lighting for the human circadian clock: recent research indicates that lighting has become a public health issue. Med. Hypotheses 63, 588-596 (2004).

36. Brainard, G. C., Richardson, B. A., King, T. S. \& Reiter, R. J. The influence of different light spectra on the suppression of pineal melatonin content in the Syrian hamster. Brain Res. 294, 333-339 (1984).

37. Hätönen, T., Alila-Johansson, A., Mustanoja, S. \& Laakso, M.-L. Suppression of melatonin by 2000-lux light in humans with closed eyelids. Biol. Psychiatry 46, 827-831 (1999).

38. Czeisler, C. A. et al. Suppression of melatonin secretion in some blind patients by exposure to bright light. New Engl. J. Med. 332, 6-11 (1995).

39. Lupan, O., Pauporté, T., Le Bahers, T., Viana, B. \& Ciofini, I. Wavelength-emission tuning of $\mathrm{ZnO}$ nanowire-based light-emitting diodes by $\mathrm{Cu}$ doping: experimental and computational insights. Adv. Funct. Mater. 21, 3564-3572 (2011).

40. Zeng, $\mathrm{H}$. et al. Blue luminescence of $\mathrm{ZnO}$ nanoparticles based on non-equilibrium processes: defect origins and emission controls. Adv. Funct. Mater. 20, 561-572 (2010).

41. Djurišić, A. et al. Defect emissions in ZnO nanostructures. Nanotechnology 18, 095702 (2007).

42. Kiliani, G. et al. Ultraviolet photoluminescence of $\mathrm{ZnO}$ quantum dots sputtered at room-temperature. Opt. Express 19, 1641-1647 (2011).

\section{Acknowledgments}

The author acknowledges the Aim for the Top University Project of the National Taiwan University provides financial support to the research. The contract number is 102R7607-1. We also thank National Science Council, Taiwan (R.O.C.), for supporting this work with the contract number of NSC 100-2221-E-002-158-MY3.

\section{Author contributions}

P.C.S., M.S.L. and C.F.L. conceived and designed the experiments. P.C.S. and M.S.L. synthesized the materials and performed the measurements. P.C.S. and C.F.L. interpreted and analyzed the data. P.C.S. and C.F.L. prepared the manuscript. 


\section{Additional information}

Supplementary information accompanies this paper at http://www.nature.com/ scientificreports

Competing financial interests: The authors declare no competing financial interests. How to cite this article: Shen, P.-C., Lin, M.-S. \& Lin, C.-F. Environmentally Benign Technology for Efficient Warm-White Light Emission. Sci. Rep. 4, 5307; DOI:10.1038/ srep05307 (2014) (i) $\Theta$ This work is licensed under a Creative Commons Attribution-NonCommercialNoDerivs 4.0 International License. The images or other third party material in this article are included in the article's Creative Commons license, unless indicated otherwise in the credit line; if the material is not included under the Creative Commons license, users will need to obtain permission from the license holder in order to reproduce the material. To view a copy of this license, visit http:// creativecommons.org/licenses/by-nc-nd/4.0/ 